\title{
Bionomics and vectorial role of anophelines in wetlands along the volcanic chain of Cameroon
}

\author{
Nathalie Amvongo-Adjia ${ }^{1,2,3^{*}}$ (D), Emmanuela L. Wirsiy ${ }^{2,4}$, Jacob M. Riveron ${ }^{5}$, Winston P. Chounna Ndongmo ${ }^{2,4}$, \\ Peter A. Enyong ${ }^{2,4}$, Flobert Njiokou ${ }^{1,6}$, Charles S. Wondji, ${ }^{5,6}$ and Samuel Wanji ${ }^{2,4^{*}}$
}

\begin{abstract}
Background: The epidemiological profiles of vector-borne diseases, such as malaria, are strongly associated with landscape components. The reduction of malaria burden in endemic and epidemic regions mainly depends on knowledge of the malaria-transmitting mosquito species, populations and behavioural characteristics, as well as malaria exposure risks. This work aimed at carrying out a holistic study in order to characterise Anopheles species in relation to human malaria in seven wetlands along the lower section of the volcanic chain of Cameroon.

Results: Eight malaria vectors: Anopheles arabiensis, An. coluzzii, An. funestus (s.s.), An. gambiae, An. hancocki, An. melas, An. nili and An. ziemanni, were found biting humans. Anopheles gambiae was widespread; however, it played a secondary role in the Ndop plain where An. ziemmani was the primary vector species (79.2\%). Anophelines were more exophagic (73.6\%) than endophagic (26.4\%), showing a marked nocturnal activity (22:00-4:00 h) for An. coluzzii and An. gambiae while An. funestus (s.s.) was mostly caught between 1:00 and 6:00 h and An. ziemanni having an early evening biting behaviour (18:00-00:00 h). Female Anopheles were mostly observed to have relative high parity rates ( $\geq$ $70 \%$ ), with the exception of the Meanja site where species parity varies from 46 to $55 \%$. Overall, the transmission level was low with entomological inoculation rates estimated to 0.7 infected bites per person per month (ib/p/mth) in Tiko and Ndop, $1.4 \mathrm{ib} / \mathrm{p} / \mathrm{mth}$ in Mamfe and $2.24 \mathrm{ib} / \mathrm{p} / \mathrm{mth}$ in Santchou.
\end{abstract}

Conclusions: The present study represents detailed Anopheles vector characterisation from an understudied area along the volcanic chain of Cameroon with endemic malaria transmission. The significant differences in bionomics and Anopheles species distribution within the studied wetlands, highlights the importance of providing baseline data and an opportunity to assess the outcome of ongoing malaria control interventions in the country.

Keywords: Malaria, Anopheles vectors, Volcanic chain of Cameroon, Wetlands, Volcanic massif

\section{Background}

Malaria, transmitted by the bite of infected female Anopheles mosquitoes, is a major health burden in the Cameroon hill tracts [1-5]. The area has an estimated Plasmodium falciparum prevalence rate (PfPR) ranging from 50 to $70 \%$, thus the disease remains the leading cause of consultation in health services [6, 7]. Although

\footnotetext{
* Correspondence: amvongo.n@gmail.com; samwandji@gmail.com ${ }^{1}$ Parasitology and Ecology Laboratory, Animal Biology and Physiology Department, Faculty of Science, University of Yaoundé 1, Yaoundé, Cameroon

${ }^{2}$ Research Foundation for Tropical Diseases and the Environment (REFOTDE), Buea, Cameroon

Full list of author information is available at the end of the article
}

there are 48 Anopheles species recorded throughout Cameroon, only 18 are responsible for malaria transmission [8-11]. These include: Anopheles arabiensis, An. coluzzii, An. gambiae and An. funestus (s.s.) as dominant vectors species, while $A n$. carnevalei, An. coustani, An. hancocki, An. leesoni, An. marshallii, An. melas, An. moucheti, An. nili, An. paludis, An. pharoensis, An. ovengensis, An. rivulorum-like, An. wellcomei and An. ziemanni play a secondary role.

Various factors contribute to differing malaria epidemiological profiles including altitude, topography, hydrology and land use/land cover types [12, 13]. Specifically, changes of environmental factors can impact

(C) The Author(s). 2018 Open Access This article is distributed under the terms of the Creative Commons Attribution 4.0 International License (http://creativecommons.org/licenses/by/4.0/), which permits unrestricted use, distribution, and 
malaria transmission by altering the microclimate of the immature stages and adult mosquitoes [14, 15], as it has been observed that the shortening of Plasmodium sporogony and vector gonotrophic cycle lead to an increase of the malaria transmission risk across highlands [16]. Furthermore, malaria prevalence is related to the existence of wetlands or swampy areas, because mosquitoes require stagnant water as their larval habitat $[17,18]$. In fact, along the volcanic chain of Cameroon (VCC), there exist a considerable number of wetlands in valley bottoms of mountain massifs that are maintained by high annual precipitation and favourable surface hydrology [19]. Of further note, these volcanic mountains possess highly fertile and productive soils resulting in a concentration of human populations [20,21].

The level of malaria transmission is determined by the interactions between Plasmodium parasites, the Anopheles vectors and the human host. Understanding adult vector population dynamics by identifying the different species, their abundance, biting behaviour and entomological inoculation rates are important steps towards effective control of malaria, with vector abundance being a key determinant of malaria transmission force [22]. Potential reductions of the malaria burden in endemic and epidemic regions depends on knowledge of the malaria-transmitting mosquito species, populations and behavioural characteristics, and malaria exposure risks. While vector populations have been extensively studied in urban [23-25], forested [26-28] and savannah $[9,29-31]$ areas of Cameroon, only a few studies on malaria vector populations have been conducted in some isolated wetlands across the VCC $[1,2,4,5]$. This disparity in the level of knowledge of the malaria vectorial system (species composition, feeding behaviour, biting cycle, entomological indices of transmission) between the Cameroon hill tract and the rest of the country is mainly due to the difficult access towards those areas. In this study, sampling was carried out in seven wetlands along the lower section of the $\mathrm{VCC}$ in order to assess the bionomics and vectorial role of Anopheles species in relation to human malaria.

\section{Methods}

\section{Study sites}

The volcanic chain of Cameroon is a $1600 \mathrm{~km}$ long massif of cenozoic volcanic and subvolcanic complexes that straddles the continent-ocean boundary. It extends from the Gulf of Guinea to the interior of the African continent. In Cameroon, it starts with Mount Cameroon, extends to the Western High Plateau and northeast towards Lake Chad (see Additional file 1: Figure S1). The line strikes almost south-west to north-east, forming a swell and basin structure where the six islands and the four central volcanoes of Mount Cameroon, Kupe Manengouba, Bamboutous, Bamenda and Oku represent swells. The presence of these large land masses and several volcanic cones facilitate the occurrence of orographic uplift, which accounts for the intensive precipitation resulting on a major input water into the wetlands [32].

Many wetlands exist in Cameroon, with some located inland and across the national frontier, and others located within the coastal lowlands of mountain massifs. Some of these wetlands result from lava filled depressions, topographic channels which widen into flood plains and braided profiles, tidal activities in estuarine environments and shallow depressions beside the coast $[33,34]$. For the current study, seven wetlands surrounded by five volcanic massifs along the lower section of the Cameroon volcanic line were selected (Fig. 1, Additional file 2: Table S1). These were: (i) Mount Cameroon massif: Tiko [4 $4^{\circ} 07^{\prime} \mathrm{N}, 9^{\circ} 36^{\prime} \mathrm{E}, 64 \mathrm{~m}$ above sea level (masl)], Kumba $\left(4^{\circ} 38^{\prime} \mathrm{N}, 9^{\circ} 27^{\prime} \mathrm{E}, 240\right.$ masl) and Meanja $\left(4^{\circ} 43^{\prime} \mathrm{N}, 9^{\circ} 38^{\prime} \mathrm{E}, 305 \mathrm{masl}\right)$; (ii) Western Highlands: Mamfe $\left(5^{\circ} 46^{\prime} \mathrm{N}, 9^{\circ} 17^{\prime} \mathrm{E}, 126 \mathrm{masl}\right)$; (iii) Mount Kupe Manengouba: Santchou $\left(5^{\circ} 15^{\prime} \mathrm{N}, 9^{\circ} 50^{\prime} \mathrm{E}, 750 \mathrm{masl}\right)$; (iv) Bamboutos: Ndop plain ( $5^{\circ} 56^{\prime} \mathrm{N}, 10^{\circ} 32^{\prime} \mathrm{E}, 1152$ masl); and (v) Mount $\mathrm{Oku} / \mathrm{Ndu}$ massif: Mbaw plain $\left(5^{\circ} 55^{\prime} \mathrm{N}\right.$, $10^{\circ} 10^{\prime} \mathrm{E}, 400$ masl).

\section{Study design and adult mosquito sampling}

Repeated cross-sectional surveys were carried out to conduct this study (see Additional file 3: Figure S2). Mosquito collections were undertaken using landing catches on human volunteers (human-landing catch: HLC) during the rainy season months of April and May 2010 (beginning of rainy season for Tiko, Meanja and Santchou), September and October 2013, and October 2014 (end of rainy season for Kumba, Mamfe, Ndop and Mbaw plain). Depending on size of the volcanic massifs and/or wetlands, one to six communities were chosen as sampled stations. During five consecutive nights (from 18:00 to 6:00 h), HLCs were performed in two houses per community with one collector indoors and one outdoors (approximately $5 \mathrm{~m}$ from the main entrance) selected households (see Additional file 4: Table S2). Householders were asked to assist designated mosquito collectors (four men per night per sampled station) in each community for 5 days per study site. Using this strategy, the Anopheles species man biting rate (MBR) or Anopheles density per person per time unit (month) was estimated and used for the calculation of the entomological inoculation rates (EIR). All mosquitoes collected were placed in holding cups labelled by hour until they were processed for morphological identification.

\section{Morphological identification of Anopheles species and age-grading methods}

After being differentiated at the level of genus as Culex, Anopheles, Aedes or Mansonia, Anopheles mosquitoes 


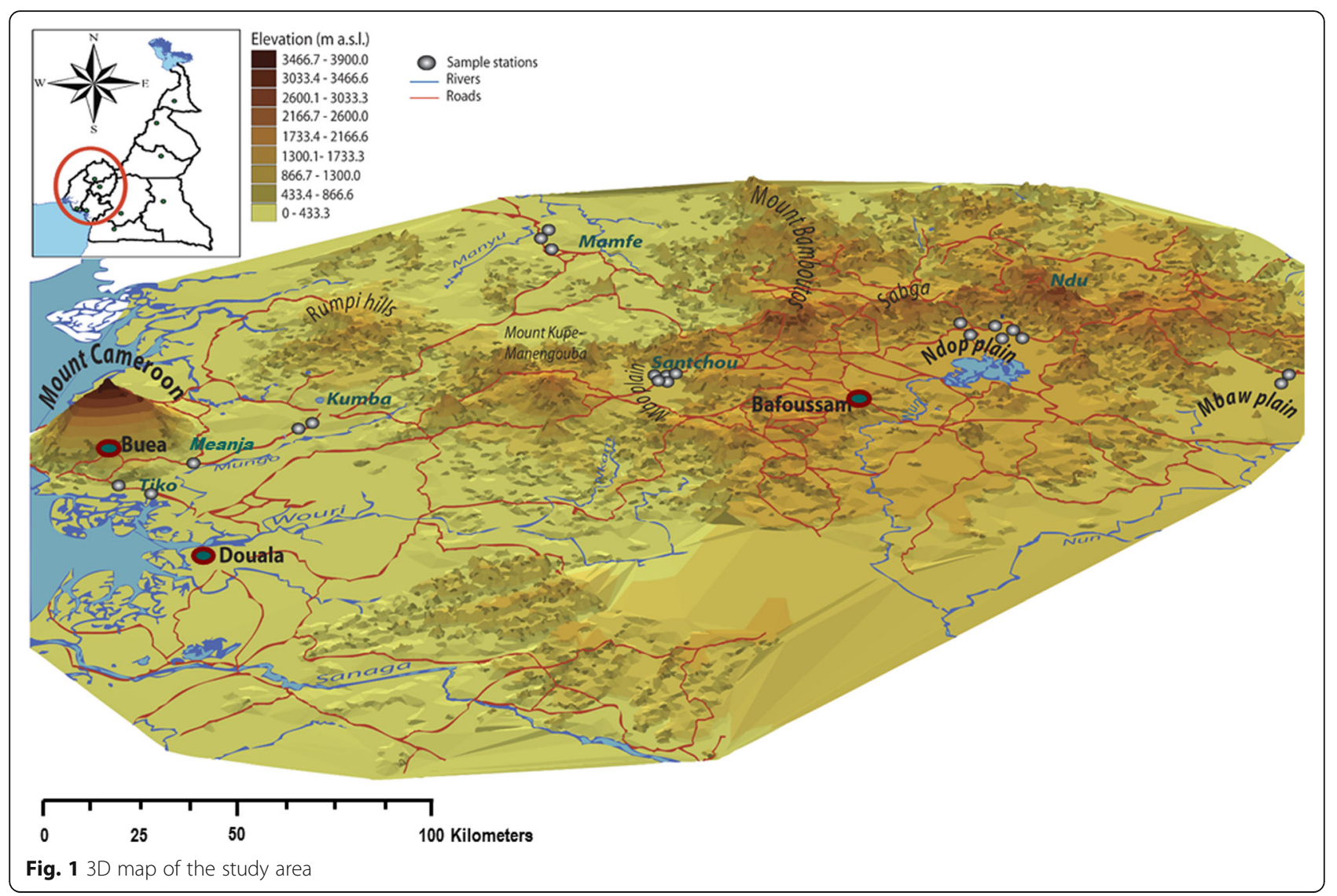

were identified to species level using the taxonomic and identification key to female Afrotropical anophelines $[35,36]$. Age-grading was based on the mosquitoes' physiological age. More precisely, the physiological age was determined from inspecting its ovaries, based on the ovary tracheation method of Detinova [37] and as described by the simplified technique of Warrel \& Gilles [38]. This dissection technique of the ovaries can differentiate parous female from nulliparous. Female Anopheles that have taken a blood meal and have laid their eggs at least once are parous, while those that have never laid eggs are nulliparous.

DNA isolation, species identification and molecular detection of Plasmodium spp. infection in Anopheles mosquitoes

Genomic DNA was individually isolated from most recurrent Anopheles specimens using a DNA extraction buffer [38]. Species were molecularly identified using sequences of the ribosomal DNA intergenic spacer (rDNA IGS) and internal transcribed spacer region 2 (ITS2) of An. gambiae (s.l.) and An. funestus (s.l.), respectively. These regions were isolated and amplified using PCR with IGS and ITS2 specific primers as previously documented $[39,40]$.
A restricted fragment length polymorphism (RFLP) was further performed on all the specimens diagnosed as An. gambiae (s.s.) to distinguish between molecular forms M and S [41]. The M molecular form of An. gambiae (s.s.) is presently known as An. coluzzii while the $\mathrm{S}$ molecular form retained the designation An. gambiae [42].

The infection status of female Anopheles was determined using a multiplex PCR for P. falciparum, $P$. malariae, $P$. vivax and $P$. ovale. Oligonucleotides were designed by Snounou et al. [43] and Padley et al. [44].

\section{Data processing and statistical analysis}

Data were compiled in EpiInfo ${ }^{\text {TM }}$ v.3.5.3 (Centre for Disease Control and Prevention, Atlanta, USA) and imported to SPSS v.20 (IBM, Chicago, USA) and GraphPad Prism v.7.0.0 for Windows (La Jolla, California, USA) for analysis. The data of malaria vector density (including diversity, biting density, biting behaviour and biting cycle) were summarized using descriptive statistics. Chi-square test was used to compare mosquito density distributions between volcanic massifs and wetlands. T-test and twoway ANOVA (on normalized data using the logarithm procedure) followed by Bonferroni's multiple comparison 
test were used to compare the mean indoor and outdoor exposure to main Anopheles vectors within and between wetlands.

Mosquito life expectancy (longevity, life span) was estimated using Davidson formula [45]:

$$
\text { Age }=\frac{1}{-\log _{e^{p}}}
$$

where "e" is the natural logarithm of the constant 2.7183 and $P$ is the probability of the vector surviving for 1 day. $P$ is calculated from the following formula:

$$
P=\sqrt[x c]{P R}
$$

where gc is the duration of the Anopheles gonotrophic cycle, the time (days) needed by a female mosquito to complete the processing of egg development in the ovaries from the blood meal to the time when the fully developed eggs are laid [46]. The parity rate (PR) is the rate of parous female Anopheles from the total number of ovaries dissected and observed. In this study, the gc anthropophagous species was 3 days while zoophagic species had a gc of 2 days [47]. The parity rate between Anopheles species and surveyed sites was compared using the Chi-square test.

The entomological inoculation rate (EIR) was calculated using the formula:

$$
E I R=I R \times M B R
$$

where IR is the rate of Anopheles tested positive for the molecular detection of Plasmodium spp. infection, and MBR the man biting rate expressed as the ratio of the number of Anopheles mosquitoes captured by HLC by the total number of man-nights.

\section{Results}

Survey summary

A total of 5918 mosquitoes were collected during the entire survey period. Four genera were recorded based on the morphological identification of the specimens (Fig. 2): Aedes (5.4\%), Culex (12.9\%), Anopheles (38.6\%) and Mansonia (43.1\%). The Mount Cameroon massif had the highest number of Anopheles specimens caught $(53.5 \%)$ while the Santchou valley in the Kupe Manengouba massif had the lowest contribution (6.2\%). Except in Mount Cameroon (Tiko, Kumba, Meanja) and Western Highlands (Mamfe) that were dominated by Anopheles mosquitoes (75.9 and 80.8\%, respectively), mosquitoes of the genus Mansonia was dominant in the Kupe Manengouba, Bamboutous and Oku volcanic massifs. For these last study sites, catches of Anopheles mosquitoes represented 10.1, 18.2 and $34.4 \%$, respectively.

\section{Anopheline species diversity and biting density}

Five Anopheles morphological species leading to eight molecular species were identified (Fig. 3): An. hancocki ( $\mathrm{n}=14$ specimens caught), An. nili ( $\mathrm{n}=19$ specimens caught), An. ziemanni ( $\mathrm{n}=213$ specimens caught), within the group of sister species An. funestus ( $n=52$ specimens caught), the sole species identified molecularly was An. funestus (s.s.) and within the complex $A n$. gambiae (s.l.) ( $n=1990$ specimens caught), four species were identified throughout this study: An. arabiensis (1.0\%), An. melas (6.7\%), An. coluzzii (34.5\%) and An. gambiae (56.4\%). Additionally, some hybrids An. coluzzii $\times$ An. gambiae (1.3\%) were also molecularly identified within the Gambiae complex in Kumba, Mamfe and Ndop sites.

Anopheles coluzzii was dominant in the western part of the study area, especially towards the sea at Tiko and Meanja, whereas An. gambiae was dominant in other sites except for the Ndop site where An. ziemanni was widely represented among night HLCs. The Mount Cameroon area had the highest species diversity [six Anopheles species out of the eight identified: An. funestus (s.s.), An. hancocki, An. nili, An. melas, An. coluzzii and An. gambiae] while only two Anopheles species (An. coluzzii and An. gambiae) were found in Mamfe towards the Western Highlands. Overall, it was noted a significant difference in the diversity of the different anopheline vectors across the study area $\left(\chi^{2}=4520.1, d f=48, P\right.$ $<0.0001)$.

\section{Biting behaviour}

The HLC collections indicated indoor and outdoor exposure of residents to host-seeking anophelines. In this study 1683 (73.6\%) of the total female Anopheles specimens collected were captured outdoors, showing a strongly exophagic biting behaviour. Two-way ANOVA test showed some significant differences in the mean number of Anopheles species caught outdoors within wetlands as well as between wetlands (see Additional file 5: Table S3), whereas only 605 (26.4\%) anophelines were captured indoors with no significant difference observed in the average number of Anopheles species caught within and between wetlands. Moreover, no statistical difference between indoor and outdoor exposure to Anopheles species was usually noted in the surveyed wetlands, except in the cities of Kumba and Mamfe where all specimens of the Gambiae complex were collected outside the houses (Fig. 4).

Comparison of anophelines biting cycle showed that dominant vectors (An. gambiae and An. coluzzii) were collected both indoors and outdoors with a significant number of bites registered late at night between 22:00 h and 4:00 h (An. coluzzii: $\chi^{2}=417.6, d f=2, P<0.0001$; An. gambiae: $\left.X^{2}=588, d f=2, \mathrm{P}<0.0001\right)$ as compared 


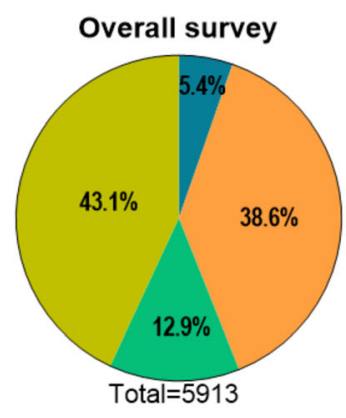

Anopheles spp.

Mansonia spp.

Aedes spp.

Culex spp.

\section{Mount Cameroon}
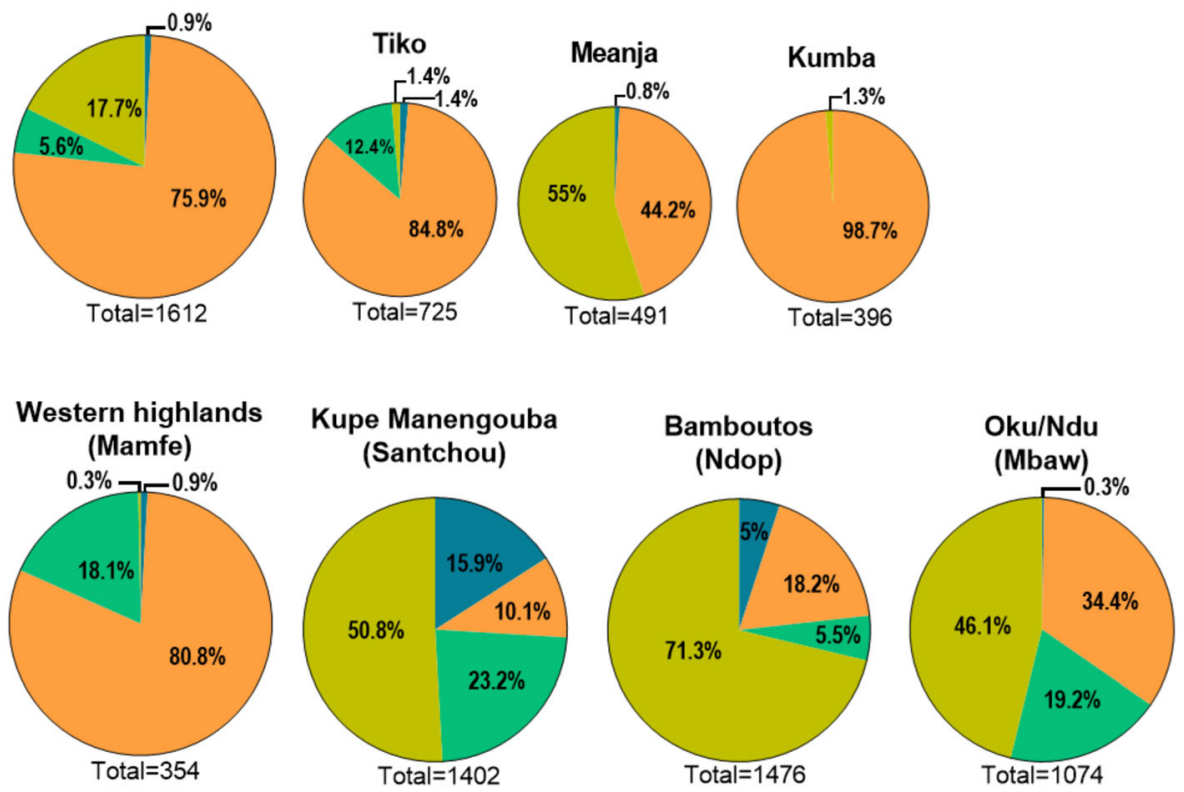

Fig. 2 Main genera of mosquitoes identified morphologically from wetlands of the different massifs of the volcanic chain of Cameroon. A significant difference based on a Chi-square test $(P<0.0001)$ was noted in the mosquito distribution for all sites

to An. funestus (s.s.) which was mostly $\left(\chi^{2}=19.69, d f\right.$ $=1, P<0.0001$ ) captured between 1:00 $\mathrm{h}$ and 6:00 $\mathrm{h}$ (Fig. 5). Indoor species were captured between 21:00 $\mathrm{h}$ and midnight. Conversely, An. ziemanni had an early evening biting behaviour (18:00-00:00 h) both indoors and outdoors $\left(\chi^{2}=59.95, d f=1, P<0.0001\right)$.

\section{Anopheles parity rate and longevity}

The parity rate (parous ratio: PR) and life expectancy or life span were analysed for Tiko (An. melas and $A n$. coluzzii), Meanja (An. funestus and $A n$. coluzzii), Santchou (An. gambiae) and Ndop (An. ziemanni and An. gambiae). PR was used to estimate mosquito longevity based on the formula proposed by Davidson [45]. Since there was no direct observation of the gonotrophic cycle (gc) value, the mosquito life span calculation used a gc value of 2 or 3 days as previously explained.
Overall, parity ratios varied from 0.55 in $A n$. funestus (s.s.) to 0.85 in An. ziemanni, whereas An. coluzzii, An. gambiae and $A n$. melas had an estimated parity of 0.67 , 0.73 and 0.79 , respectively (Table 1 ). Likewise, throughout the study area, species life expectancies estimates were: 5.02 days in An. funestus (s.s.), 7.49 days in $A n$. coluzzii, 9.53 days in An. gambiae, 12.31 days in $A n$. ziemanni and 12.73 days in An. melas. No statistical difference was observed in the distribution of parity rate between species; however, only $A n$. coluzzii exhibited significant different parous rates per site $\left(\chi^{2}=10.25, d f\right.$ $=1, P=0.0014$ ) while comparing the Tiko and Meanja surveys.

Plasmodium infection and entomological inoculation rates A total of 2209 Anopheles mosquitoes [20 An. arabiensis, 51 An. funestus (s.s.), 131 An. melas, 213 An. ziemanni, 685 An. coluzzii and 1109 An. gambiae] were 

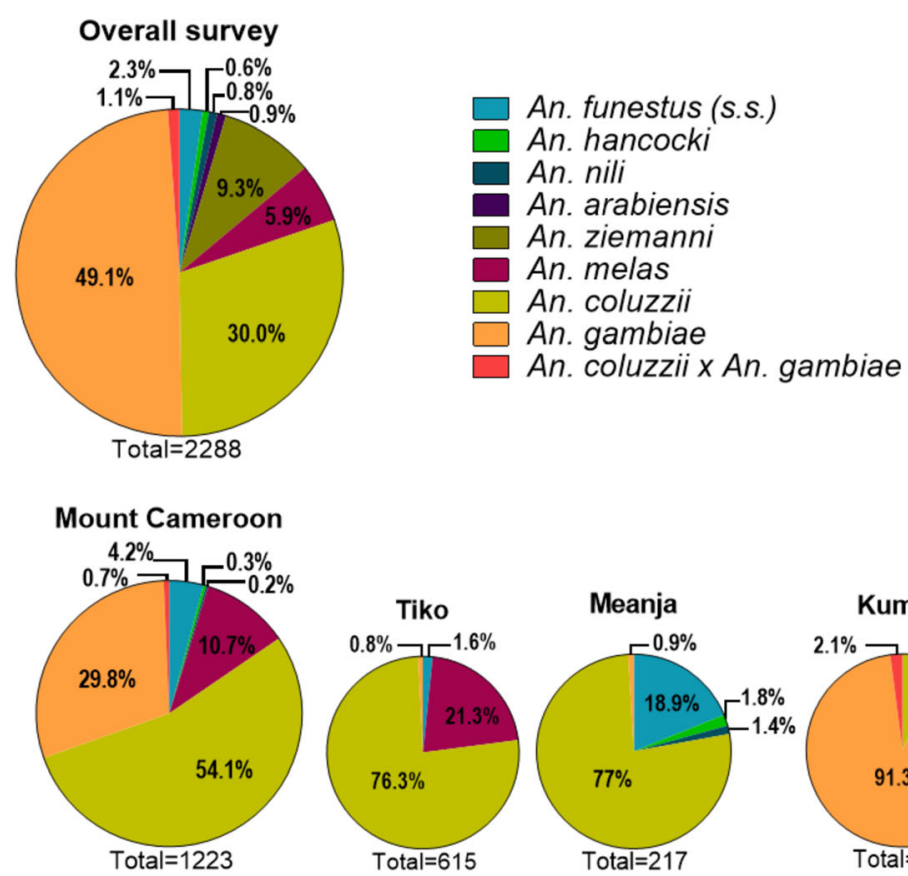

Kumba
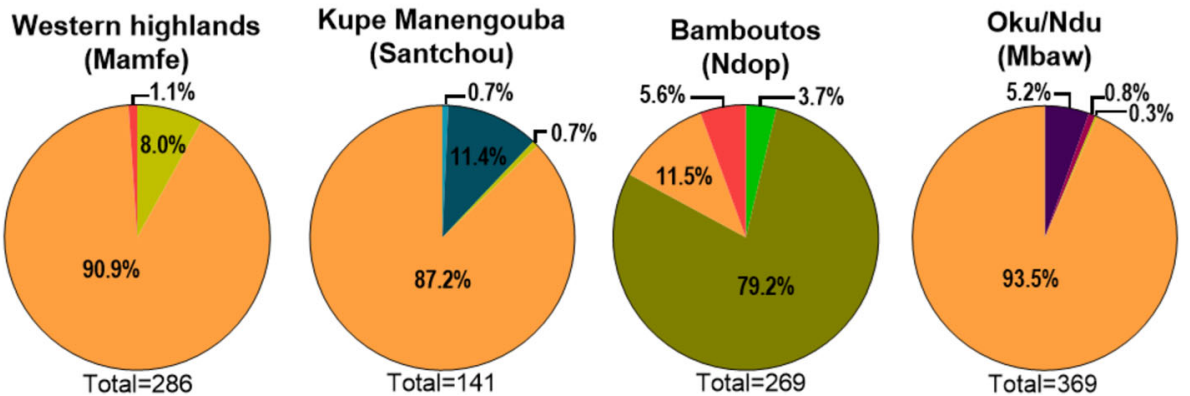

Fig. 3 Diversity of Anopheles species (identified morphologically and using molecular techniques) from wetlands of major volcanic massifs across the study area. A significant difference based on a Chi-square test $(P<0.0001)$ was noted in anopheline abundance in all sites

tested for Plasmodium infection using a TaqMan assay. Only three Anopheles species were found positive during the molecular detection of Plasmodium infection, namely An. coluzzii (0.15\%), An. gambiae (1.08\%) and An. ziemanni (1.41\%) (Table 2). Infected Anopheles were found only in four wetlands out of the seven surveyed: Tiko (An. coluzzii), Mamfe (An. gambiae), Santchou (An. gambiae) and Ndop (An. gambiae and An. ziemanni). Infection rates (IRs) varied between Anopheles species and wetlands and ranged between $0-6.9 \%$ with no statistical difference (based on Chi-square tests) found between anophelines and wetlands. Anopheles coluzzii was the species most commonly found biting humans with a man biting rate (MBR) of 328.3 bites per person per month (b/p/mth) while for An. gambiae it ranged from $7.2 \mathrm{~b} / \mathrm{p} / \mathrm{mth}$ in Ndop to $121.3 \mathrm{~b} / \mathrm{p} / \mathrm{mth}$ in Mamfe, and An. ziemanni had $49.7 \mathrm{~b} / \mathrm{p} / \mathrm{mth}$. Thus, the level of overall malaria transmission varies between Anopheles species and wetlands. An. gambiae appears to be the most frequently competent malaria vector with entomological inoculation rates (EIRs) estimated at 0.23 infected bites per person per month $(\mathrm{ib} / \mathrm{p} / \mathrm{mth})$ in Ndop, $1.4 \mathrm{ib} / \mathrm{p} / \mathrm{mth}$ in Mamfe and $2.24 \mathrm{ib} / \mathrm{p} / \mathrm{mth}$ in Santchou. However, similar EIRs $(0.7 \mathrm{ib} / \mathrm{p} / \mathrm{mth})$ were observed for An. coluzzii in Tiko and An. ziemanni in Ndop.

\section{Discussion}

Malaria remains a significant public health problem in Cameroon. Using standard procedures of collecting and processing samples, this study demonstrates the wide range of vector composition and distribution, exposure in sampled sites, and entomological indices of transmission in seven wetlands along the downer section of the VCC.

During this study, Anopheles and Mansonia were the most predominant culicid genera found throughout the study area. The Mount Cameroon massif contributed up to $75.9 \%$ of the entire Anopheles fauna collected while 


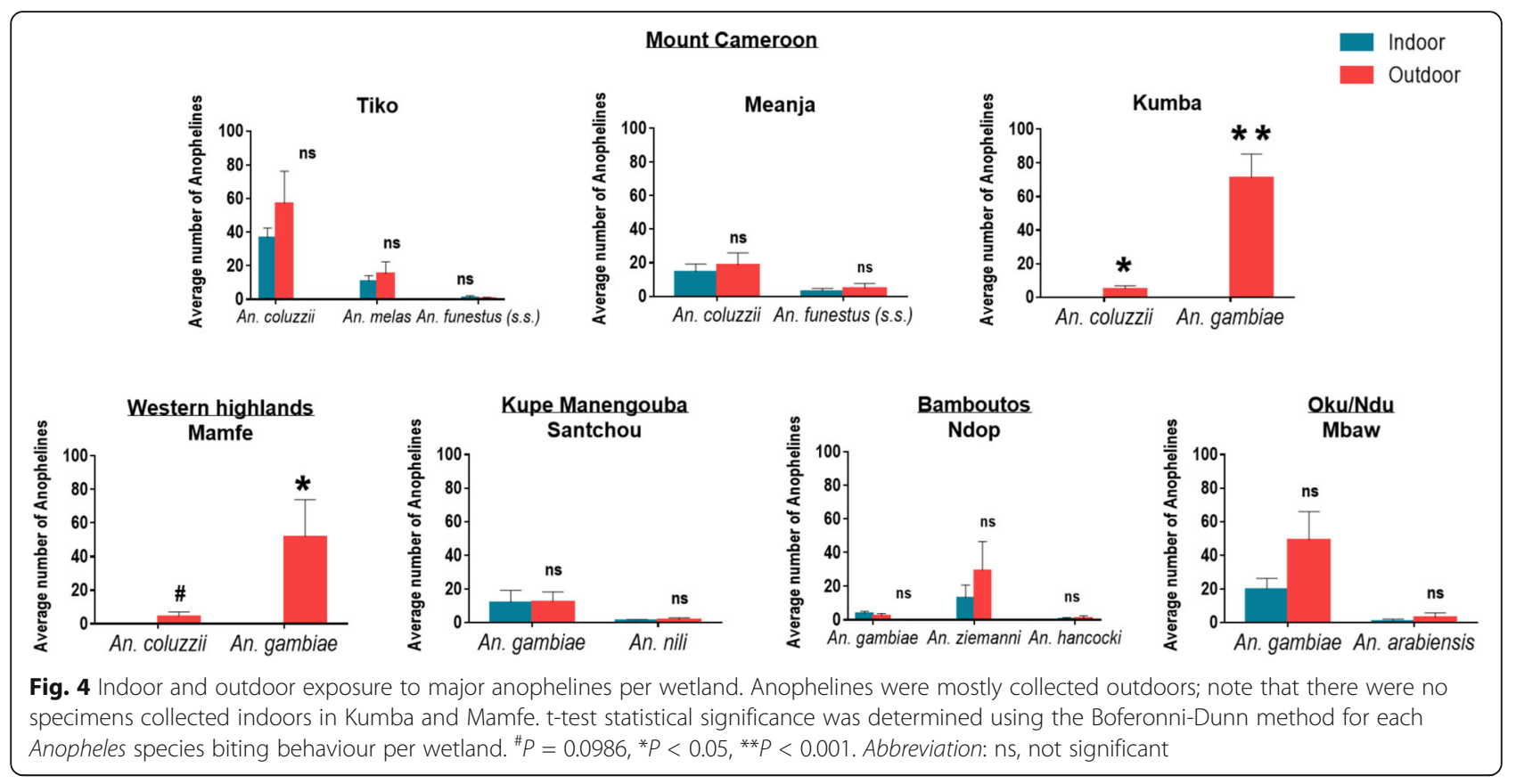

Mansonia species were mostly associated with rice flood plains (Santchou, Ndop and Mbaw). These observations were contrary to other studies which associated Anopheles mosquitoes with a wide range of habitats including rice field ecosystems [48-50], whereas Mansonia species showed a preference to ponds infested with Pistia spp. which are also common in such areas [51]. In addition to the species of these genera, Aedes spp. and Culex spp. were also encountered in wetlands of the VCC. In Africa, these mosquitoes are known to transmit Wuchereria bancrofti microfilariae, the causative agents of lymphatic filariasis in Africa (mainly Anopheles spp. and Culex spp.), and viruses causing dengue fever and yellow fever (Aedes spp.) as well as Rift Valley fever (Culex spp. and Aedes spp., but also Anopheles spp. and Mansonia spp. in the enzootic cycle in East Africa).

All five morphological malaria vector taxa (leading to eight molecular species) recorded in Cameroon [8-11] were found biting humans along the volcanic chain of Cameroon. High species diversity was noted in the Mount Cameroon massif (6 out of 8 species), Kupe Manengouba and Oku massifs (4 out of 8 species each), whereas only two Anopheles species were found in the Western Highlands and Oku massifs, with observations being in accordance with previous reports $[1,4,5]$.

The most widespread and competent malaria vector in sub-Saharan Africa, An. gambiae, was found to be present throughout the studied wetlands. Its distribution

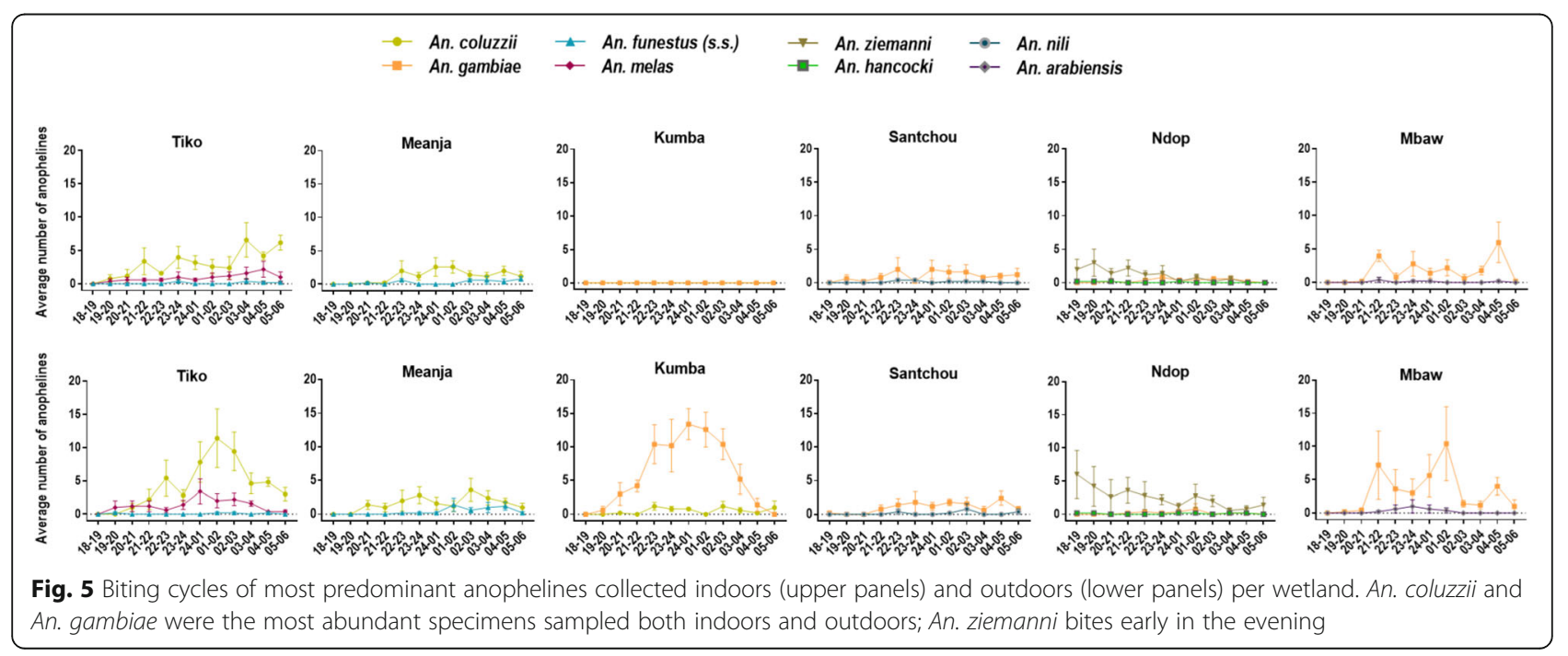


Table 1 Parous rate and duration of life expectancy of Anopheles species from the different study sites

\begin{tabular}{llllllll}
\hline Volcanic massif & Wetland $^{\text {a }}$ & Species & Dissected & Parous & PR & $P^{\text {b }}$ & Life span (days) \\
\hline Mount Cameroon & Tiko & An. melas & 99 & 78 & 0.79 & 0.92 & 12.73 \\
& & An. coluzzii & 337 & 261 & 0.77 & 0.92 & 11.48 \\
& Meanja & An. funestus (s.s.) & 38 & 21 & 0.55 & 0.82 & 5.02 \\
Kupe Manengouba & & An. coluzzii & 157 & 72 & 0.46 & 0.77 & 3.86 \\
Bamboutos & Santchou & An. gambiae & 116 & 80 & 0.69 & 0.88 & 8.08 \\
& Ndop & An. ziemanni & 181 & 154 & 0.85 & 0.92 & 12.31 \\
& & An. gambiae & 31 & 28 & 0.90 & 0.97 & 28.47 \\
\hline
\end{tabular}

No Anopheles dissected in Kumba, Mamfe and Mbaw plain

${ }^{b}$ No statistical difference was observed in the distribution of parity rate between species; however, a significant difference $($ Chi-square test: $P<0.05)$ was noted in the An. coluzzii parous rate while comparing Tiko and Meanja sites

Abbreviations: $P R$ parous ratio, $P$ probability of daily survival

and predominance are consistent with previous studies $[1,9,52,53]$. The adaptability of this species to different topographic settings has also been widely reported $[4,10]$. In Ndop, although An. gambiae and An. ziemanni were both involved in malaria transmission, the dominant vector was An. ziemanni. Here, the high density of An. ziemanni was probably a consequence of the ecosystem consisting of paddy fields irrigated by water (vegetative swamps) sourcing from numerous natural lakes, which enables the proliferation of breeding sites that favour its development [5, 54]. The localised predominance of $A n$. ziemanni has been previously observed in the same region [5], as well as in western Kenya [55] and south-central Ethiopia [54] where the swamps contain a lot of aquatic vegetation as with Ndop plain.

The two sibling species of Anopheles coluzzii and An. gambiae were spatially segregated across the study sites. This is in-line with observations made by other studies $[42,56]$ which report that these molecular forms are cohesive and constitute exclusive taxonomic groups across their shared range. An. coluzzii is more adapted to urbanized and polluted environments (such as Tiko and Meanja) [57], and environments having high salinity rates [58], while $A n$. gambiae seems predominant in semi-urban, rural and arid environments (such as Kumba, Mamfe, Santchou and Mbaw plain) [59]. Hybridization between forms occurs rarely $(\sim 1 \%)$ in Central Africa [60, 61] as confirmed in our study where a low rate of $A n$. coluzzii $\times$ An. gambiae hybrids was noted. Furthermore, $5.6 \%$ of An. coluzzii $\times$ An. gambiae hybrids in the Ndop area was noted, whereas only $A n$. gambiae molecularly identified, opposing observations made by Tabue et al. [5] who reported An. coluzzii in the same region. Nevertheless, this difference could be justified by the fact that during this study investigators surveyed different sampled stations than the previous team. Thus, more studies should be conducted in the Ndop area in order to understand the distribution of $A n$.

Table 2 Infection rate and weekly entomological inoculation rate of Anopheles vectors in the study site

\begin{tabular}{|c|c|c|c|c|c|c|c|}
\hline Volcanic massif & Wetland & Species & Tested & Positive & IR (\%) & MBR (b/p/mth) & EIR (ib/p/mth) \\
\hline \multirow[t]{7}{*}{ Mount Cameroon } & \multirow[t]{3}{*}{ Tiko } & An. coluzzii & 469 & 1 & 0.21 & 328.3 & 0.70 \\
\hline & & An. melas & 131 & 0 & 0 & 91.7 & 0 \\
\hline & & An. funestus (s.s.) & 10 & 0 & 0 & 7.0 & 0 \\
\hline & \multirow[t]{2}{*}{ Meanja } & An. coluzzii & 167 & 0 & 0 & 116.9 & 0 \\
\hline & & An. funestus & 41 & 0 & 0 & 28.7 & 0 \\
\hline & \multirow[t]{2}{*}{ Kumba } & An. coluzzii & 26 & 0 & 0 & 18.2 & 0 \\
\hline & & An. gambiae & 357 & 0 & 0 & 249.9 & 0 \\
\hline \multirow[t]{2}{*}{ Western Highlands } & \multirow[t]{2}{*}{ Mamfe } & An. coluzzii & 23 & 0 & 0 & 16.1 & 0 \\
\hline & & An. gambiae & 260 & 3 & 1.15 & 121.3 & 1.40 \\
\hline Kupe Manengouba & Santchou & An. gambiae & 116 & 8 & 6.90 & 32.5 & 2.24 \\
\hline \multirow[t]{2}{*}{ Bamboutos } & \multirow[t]{2}{*}{ Ndop } & An. gambiae & 31 & 1 & 3.22 & 7.2 & 0.23 \\
\hline & & An. ziemanni & 213 & 3 & 1.41 & 49.7 & 0.70 \\
\hline \multirow[t]{2}{*}{ Oku/Ndu } & \multirow[t]{2}{*}{ Mbaw } & An. arabiensis & 20 & 0 & 0 & 4.7 & 0 \\
\hline & & An. gambiae & 345 & 0 & 0 & 80.5 & 0 \\
\hline
\end{tabular}


gambiae (s.s.) (formerly grouping An. gambiae $\mathrm{M}$ and $\mathrm{S}$ molecular forms) species.

Other malaria vectors such as An. funestus (s.s.), An. nili and $A n$. hancocki were recorded in the Mount Cameroon, Kupe Manengouba and Ndu massifs. These are secondary malaria vectors in forested areas $[1,2,62,63]$ even if $A n$. funestus (s.s.) has been reported as primary malaria vector in Savannah areas [29, 30, 64]. The presence of $A n$. melas in the coastal plain (Tiko) confirms its association with saltwater where its larvae develop [2, 61]. Anopheles arabiensis occurred exclusively in the SudanSavannah domain (Mbaw plain), in agreement with literature data $[52,61,65]$.

Overall, the anopheline fauna were more frequently caught outdoors $(73.6 \%)$ than indoors $(26.4 \%)$. However, the biting behaviour should be considered for each Anopheles spp. in each wetland as there was considerable variation. For example, in Kumba and Mamfe, both An. gambiae and An. coluzzii were exclusively exophagic, while in Meanja there was both indoor and outdoor biting of these sibling species. To calculate the extent of transmission that occurs outdoors, it is important to consider the location of the human population during peak biting times, because if biting is primarily nocturnal then the majority of the humans may be indoors. This was demonstrated in south Cameroon where An. gambiae (s.l.) was found both outdoors and indoors [11], although $52-85 \%$ of An. gambiae (s.l.) bites occurred indoors as observed by Antonio-Nkondjio et al. [26] when studying malaria transmission dynamics. On the other hand, An. funestus (s.l.) has a preference for indoor-feeding but a significant percentage of bites occur outdoors [66] as well as An. ziemanni [5]. Killeen et al. [67] had recently shown that although most outdoor malaria transmission is due to a behavioural resistance mechanism, each individual mosquito does have opportunities to enter houses during the extrinsic incubation period and could be potentially exposed to indoor control tools. However, further studies are urgently needed in Kumba and Mamfe in order to assess the extent of outdoor transmission and potential vector control measures that could be implemented in those areas.

Anopheles gambiae and An. coluzzii showed a marked nocturnal activity with intense human bites taking place between 22:00 $\mathrm{h}$ and 4:00 h while An. funestus (s.s.) was mostly caught from 1:00 to 6:00 h. These observations are consistent with others studies $[1,11,66]$ which reported that members of the An. gambiae complex and An. funestus group mostly bite late at night, between midnight and the early hours of the morning (00:005:00 h), contrasting with An. ziemanni whose biting activity declined throughout the night with a peak period early in the evening until midnight (18:00-00:00 h). This later species when in sympatry with An. gambiae could ensure an increased risk of malaria transmission as previously observed in Ethiopia by Kenea et al. [54]. However, there is no evidence of that the early biting behaviour observed in An. ziemanni in this study or in others is a result of behavioural modifications or shifts.

This study revealed relatively high parity rates of female Anopheles $(\geq 70 \%)$ in the study area, except the Meanja site $(\leq 55 \%)$ in the Mount Cameroon massif. These variations underline the great variability of parity rates observed sometimes between study sites, and within the same site depending on the species density dynamics. High parous rates could be influenced by temporal fluctuations such as the beginning of rainfall coupled to the emergence of nulliparous individuals (for example, in Tiko, Meanja and Santchou, mosquitoes were collected after the dry period) or associated with the non-application of control measures, thus leading to an accumulation of older populations with time [68], especially in the Ndop plain where An. gambiae had the highest life expectancy (28.47 days). The parous ratio and longevity of An. gambiae in Santchou was comparable to data obtained by Tchuinkam et al. [4] when studying the bionomics of Anopheles species and malaria transmission in the same area. Alternatively, the low parous rate and consequently the decrease in longevity of An. coluzzii in Meanja, could be further investigated and associated to the application of control measures and malaria endemicity level in this area.

Overall, the transmission of malaria in the wetlands of the volcanic chain of Cameroon seemed to be low as shown by an overall EIR ranging from 0.23 to 2.24 infected bites per person per month. Although An. coluzzii was the most commonly found biting humans and its sibling An. gambiae was the most frequently tested positive to Plasmodium infection, infection rates showed no significant difference between anophelines tested positive for Plasmodium infection. These observations are in-line with that of Gnémé et al. [69] who showed that there was no difference between An. coluzzii and An. gambiae in their infection susceptibility to Plasmodium falciparum. Moreover, An. gambiae, generally known to be the main malaria vector in most areas of the southern forested parts of the country $[2,70]$, played a secondary role in Ndop. The contribution of $A n$. ziemanni in the Ndop plain (0.7 infected bites per month) is comparable with values obtained by Tabue et al. [5] in the same area, and comparable with its low anthropophagy as previously shown [71, 72]. However, this species has been previously reported to play a secondary role in the transmission of malaria in several eco-epidemiological settings of Cameroon $[2,9]$.

\section{Conclusions}

To our knowledge, this study represents the most formal and extensive work available to date of Anopheles 
species in wetlands along the lower section of the volcanic chain of Cameroon. Eight Anopheles species were present across the study area, all known to be potential malaria vectors in Cameroon. Anopheles gambiae was widespread and probably the main vector in the land, whereas in coastal areas $A n$. coluzzii dominated. These dominant vector species were relayed by other species of Anopheles, sometimes of considerable local importance such as An. ziemanni in the Ndop plain. The unequal distribution of the Anopheles species within the studied wetlands, may further confirm that the occurrence of these mosquitoes truly varies according to macro- and microenvironmental differences exhibited by different bio-ecological areas. Most of the host-seeking vectors showed a preference for feeding outdoors rather than indoors which could be a challenge to the malaria control strategies which uses mainly predominantly indoor control intervention tools such as long-lasting insecticidal nets (LLINs) and indoor residual spraying (IRS). Of further challenge is the observation that these mosquitoes were found biting early in the evening as well as late in the night depending on the species when people might not be protected by LLINs. A regular update of vector species is thus necessary for effective malaria control.

\section{Additional files}

Additional file 1: Figure S1. Cameroon volcanic line. (PDF 405 kb)

Additional file 2: Table S1. Summary information of the surveyed wetlands and environmental factors. (PDF 194 kb)

Additional file 3: Figure S2. Flow chart of activities. (PDF $47 \mathrm{~kb}$ ) Additional file 4: Table S2. Sampling parameters for mosquito collections. (PDF $185 \mathrm{~kb}$ )

Additional file 5: Table S3. Two-way ANOVA statistical significance for each outdoor-biting Anopheles species within and between wetlands. (PDF $212 \mathrm{~kb})$

\section{Abbreviations}

EIR: Entomological inoculation rate; IR: Infection rate; MBR: Man-biting rate; P: Probability of daily survival; PR: Parity rate or parous ratio

\section{Acknowledgements}

The authors thank the Centre for Neglected Tropical Diseases (CNTD), Liverpool, UK, for its support through the acquisition of consumables and reagents; the populations of Tiko, Meanja, Kumba, Mamfe, Santchou, Ndop, Mbaw plain and all the mosquito collectors who willingly participated in this study; and the entire Research Foundation for Tropical Research and Environment (REFOTDE), especially the following persons: Mrs Ndamukong Judith, Ms Mafo F. Flora, Mrs Dizzle B. Tayong, Fabrice R. Datchoua, Sali Saïdou, Nkemkang Napoleon, and Mr Bonekeh J., for excellent and dedicated collaboration during the field surveys.

\section{Funding}

Not applicable.

\section{Availability of data and materials}

All data generated or analysed during this study are included within the article and its additional files. In addition, a minimal dataset can be accessed upon request by writing to the data management unit of Research
Foundation for Tropical Diseases and Environment (REFOTDE) at Natyadji@yahoo.fr.

\section{Authors' contributions}

SW and NJ conceived and designed the study. NAA, ELW, WPCN and PAE managed field studies. NAA and ELW performed the molecular experiments with the contribution from WPCN. NAA analysed the data with contribution from JMR and ELW. NAA, JMR and CSW wrote the manuscript with contribution from all authors. All authors read and approved the final manuscript.

\section{Ethics approval and consent to participate}

The protocol used for this study received ethical approval from the Cameroon National Ethics Committee (CNEC) and administrative approval from the Ministry of Public Health of Cameroon. The various aspects of the work were conducted in collaboration with the local district administration. In each community, details were given about potential risks and benefits of the study to the community leaders, head of households and potential mosquito collectors. It was explained that participation was voluntary, and investigators provided a written informed consent form which was signed by the head of households and mosquito collectors. Households were sprayed at the end of the survey, and presumptive malaria treatment was given throughout the study to mosquito collectors as recommended by the National Malaria Control Programme.

\section{Consent for publication}

Not applicable.

\section{Competing interests}

The authors declare that they have no competing interests.

\section{Publisher's Note}

Springer Nature remains neutral with regard to jurisdictional claims in published maps and institutional affiliations.

\section{Author details}

'Parasitology and Ecology Laboratory, Animal Biology and Physiology Department, Faculty of Science, University of Yaoundé 1, Yaoundé,

Cameroon. ${ }^{2}$ Research Foundation for Tropical Diseases and the Environment (REFOTDE), Buea, Cameroon. ${ }^{3}$ Centre for Medical Research, Institute of Medical Research and Medicinal Plants Studies (IMPM), Yaoundé, Cameroon. ${ }^{4}$ Parasite and Vector Biology Research Unit (PAVBRU), Microbiology and Parasitology Department, University of Buea, Buea, Cameroon. ${ }^{5}$ Vector Biology Department, Liverpool School of Tropical Medicine, LiverpoolL3 5QAUK. ${ }^{6}$ Centre for Research in Infectious Diseases (CRID), LSTM Research Unit, Yaoundé, Cameroon.

Received: 27 January 2018 Accepted: 30 July 2018

Published online: 14 August 2018

References

1. Wanji S, Tanke T, Atanga S, Ajonina C, Nicholas T, Fontenille D. Anopheles species of the mount Cameroon region: biting habits, feeding behaviour and entomological inoculation rates. Trop Med Int Health. 2003;8:643-9.

2. Bigoga J, Manga L, Titanji V, Coetzee M, Leke R. Malaria vectors and transmission dynamics in coastal south-western Cameroon. Malar J. 2007:6:5.

3. Atangana J, Fondjo E, Fomena A, Tamesse J, Patchoké S, Ndjemaï H, et al. Seasonal variations of malaria transmission in Western Cameroon highlands: entomological, parasitological and clinical investigations. J Cell Anim Biol. 2009:3:33-8.

4. Tchuinkam T, Simard F, Lélé-Defo E, Téné-Fossog B, Tateng-Ngouateu A, Antonio-Nkondjio C, et al. Bionomics of anopheline species and malaria transmission dynamics along an altitudinal transect in western Cameroon. BMC Infect Dis. 2010:10:119.

5. Tabue R, Nem T, Atangana J, Bigoga J, Patchoké S, Tchouine F, et al. Anopheles ziemanni a locally important malaria vector in Ndop health district, north west region of Cameroon. Parasit Vectors. 2014;7:262.

6. Gething P, Patil A, Smith D, Guerra C, Elyazar I, Johnston G, et al. A new world malaria map: Plasmodium falciparum endemicity in 2010. Malar J. 2011;10:378.

7. World Health Organisation - Global Malaria Programme. World Malaria Report. Geneva: WHO; 2015. 
8. Fontenille D, Simard F. Unravelling complexities in human malaria transmission dynamics in Africa through a comprehensive knowledge of vector populations. Comp Immunol Microbiol Infect Dis. 2004;27:357-75.

9. Antonio-Nkondjio C, Kerah C, Simard F, Awono-Ambene P, Chouaibou M, Tchuinkam T, et al. Complexity of the malaria vectorial system in Cameroon: contribution of secondary vectors to malaria transmission. J Med Entomol. 2006;43:1215-21

10. Ayala D, Costantini C, Ose K, Kamdem K, Antonio-Nkondjio C, Agbor J, et al. Habitat suitability and ecological niche profile of major malaria vectors in Cameroon. Malar J. 2009:8:307.

11. Sinka M, Bangs M, Manguin S, Coetzee M, Mbogo C, Hemingway J, et al. The dominant Anopheles vectors of human malaria in Africa, Europe and the Middle East: occurrence data, distribution maps and bionomic précis. Parasit Vectors. 2010;3:117.

12. Pascual M, Ahumada J, Chaves $L$, Rodó $X$, Bouma M. Malaria resurgence in the East African highlands: temperature trends revisited. Proc Natl Acad Sci USA. 2006;103:5829-34.

13. Nmor J, Sunahara T, Goto K, Futami K, Sonye G, Akweywa P, et al. Topographic models for predicting malaria vector breeding habitats: potential tools for vector control managers. Parasit Vectors. 2013;6:14.

14. Clements $\mathrm{A}$. The biology of mosquitoes: development, nutrition and reproduction. vol. 1, 2nd edn. London: CABI Publishing; 2000.

15. Minakawa N, Munga S, Atieli F, Mushinzimana E, Zhou G, Githeko A, et al. Spatial distribution of anopheline larval habitats in Western Kenyan highlands: effects of land cover types and topography. Am J Trop Med Hyg. 2005;73:157-65

16. Minakawa N, Omukunda E, Zhou G, Githeko A, Yan G. Malaria vector productivity in relation to the highland environment in Kenya. Am J Trop Med Hyg. 2006;75:448-53.

17. Olson S, Gangnon R, Elguero E, Durieux L, Guégan J-F, Foley J, et al. Links between climate, malaria, and wetlands in the Amazon basin. Emerg Infect Dis. 2009;15:659-62.

18. Sousa A, Andrade F, Félix A, Jurado V, Léon-Botubol A, Garcia-Murillo P, et al. Historical importance of wetlands in malaria transmission in southwest of Spain. Limnetica. 2009;28:283-300.

19. Burke K. Origin of the Cameroon line of volcano-capped swells. J Geol. 2001;109:349-62

20. Kometa S. Wetlands exploitation along the Bafoussam - Bamenda Road axis of the Western Highlands of Cameroon. Hum Ecol. 2013;41:25-32.

21. Ramsar-Convention. Wetlands and agriculture: partners for growth, food and agricultural activities_The UN international year of family farming. International water management institute. 2014. http://www.ramsar.org/ info/values_intro_e.htm. Accessed 14 Sept 2016.

22. Garrett-Jones C. Prognosis for interruption of malaria transmission through the assessment of mosquito vectorial capacity. Nature. 1964;204:1173-5.

23. Antonio-Nkondjio C, Awono-Ambene P, Toto J, Meunier J-Y, Zebaze-Kemleu $\mathrm{S}$, Nyambam $\mathrm{R}$, et al. High malaria transmission intensity in a village close to Yaounde, the capital city of Cameroon. J Med Entomol. 2002:39:350-5.

24. Bakwo E, Akono Ntonga P, Belong P, Messi J. Contribution of mosquito vectors in malaria transmission in an urban district of southern Cameroon. J Entomol Nematol. 2010;2:13-7.

25. Akono Ntonga P, Tonga C, Mbida J, Ngo Hondt O, Awono-Ambene P, Ndo C, et al. Anopheles gambiae, vecteur majeur du paludisme à Logbessou, zone péri-urbaine de Douala (Cameroun). Bull Soc Pathol Exot. 2015;108:360-8.

26. Antonio-Nkondjio C, Simard F, Awono-Ambene P, Ngassam P, Toto J, Tchuinkam T, et al. Malaria vectors and urbanization in the equatorial forest region of south Cameroon. Trans R Soc Trop Med Hyg. 2005;99:347-54.

27. Bigoga J, Nanfack F, Awono-Ambene P, Patchoké S, Atangana J, Otia V, et al. Seasonal prevalence of malaria vectors and entomological inoculation rates in the rubber cultivated area of Niete, South Region of Cameroon. Parasit Vectors. 2012;5:197.

28. Ndo C, Simard F, Kengne P, Awono-Ambene P, Morlais I, Sharakhov I, et al. Cryptic genetic diversity within the Anopheles nili group of malaria vectors in the Equatorial forest area of Cameroon (Central Africa). PLoS One. 2013;8:e58862.

29. Robert V, van den Broeck A, Stevens P, Slootweg R, Petrarca V, Coluzzi M, et al. Mosquitoes and malaria transmission in irrigated rice-fields in the Benoue valley of northern Cameroon. Acta Trop. 1992;52:201-4.

30. Cohuet A, Simard F, Wondji C, Antonio-Nkondjio C, Awono-Ambene P, Fontenille D. High malaria transmission intensity due to Anopheles funestus (Diptera: Culicidae) in a village of savannah-forest transition area in Cameroon. J Med Entomol. 2004;41:901-5.
31. Antonio-Nkondjio C, Atangana J, Ndo C, Awono-Ambene P, Fondjo E, Fontenille $\mathrm{D}$, et al. Malaria transmission and rice cultivation in Lagdo, northern Cameroon. Trans R Soc Trop Med Hyg. 2008;102:352-9.

32. Gwanfogbe M, Meligui A, Moukam J, Nguoghia J. Geography of Cameroon. Macmillan Education: Hong Kong; 1983.

33. Fitton JG, Dunlop HM. The Cameroon Line, West Africa, and its bearing on the origin of oceanic and continental alkali basalt. Earth Planet Sci Lett. 1985;72:23-38.

34. Suh CE, Sparks RSJ, Fitton JG, Ayonghe SN, Annen C, Nana R, et al. The 1999 and 2000 eruptions of Mount Cameroon: eruption behaviour and petrochemistry of lava. Bull Volcanol. 2003;65:267-81.

35. Gillies M, Coetzee M. A supplement to the Anophelinae of Africa south of the Sahara (Afrotropical region). Johannesburg: The South African Institute for Medical Research; 1987

36. Diagne N, Fontenille D, Konate L, Faye O, Lamizana MT, Legros F, et al. Anopheles of Senegal: an annotated and illustrated list. Bull Soc Pathol Exot. 1994;4:267-77.

37. Detinova T. Age grouping methods in Diptera of medical importance with special reference to some vectors of malaria. Monogr Ser World Health Organ. 1962;47:13-191.

38. Warrel D, Gilles H. Essential malariology. 4th ed. London: Arnold; 2002.

39. Cornel AJ, Collins FH. PCR of the ribosomal DNA intergenic spacer regions as a method for identifying mosquitoes in the Anopheles gambiae complex. Methods Mol Biol. 1993;50:321-32.

40. Scott J, Brogdon W, Collins F. Identification of single specimens of the Anopheles gambiae complex by the polymerase chain reaction. Am J Trop Med Hyg. 1993;49:520-9.

41. Koekemoer L, Kamau L, Hunt R, Coetzee M. A cocktail polymerase chain reaction assay to identify members of the Anopheles funestus (Diptera: Culicidae) group. Am J Trop Med Hyg. 2002;66:804-11.

42. Fanello C, Santolamazza F, della Torre A. Simultaneous identification of species and molecular forms of Anopheles gambiae complex by PCR-RFLP. Med Vet Entomol. 2002;16:461-4

43. Coetzee M, Hunt R, Wilkerson R, Della Torre A, Coulibaly M, Besansky N. Anopheles coluzzii and Anopheles amharicus, new members of the Anopheles gambiae complex. Zootaxa. 2013:3619:246-74.

44. Snounou G, Pinheiro L, Goncalves A, Fonseca L, Dias F, Brown KN, et al. The importance of sensitive detection of malaria parasites in the human and insect hosts in epidemiological studies, as shown by the analysis of field samples from Guinea Bissau. Trans R Soc Trop Med Hyg. 1993;87:646-53.

45. Padley D, Moody AH, Chiodini PL, Saldanha J. Use of a rapid, single-round, multiplex PCR to detect malarial parasites and identify the species present Ann Trop Med Parasitol. 2003:97:131-7.

46. Davidson G. Estimation of the survival-rate of anopheline mosquitoes in nature. Nature. 1954;174:792-3.

47. White GB. The importance of Anopheles leucosphyrus group mosquitoes as vectors of malaria and filariasis in relation to transmigration and forestry in Indonesia, with assessment of Anopheles balabacensis ecology and vectorial capacity. In: World Health Organization, WHO project IR VBC 025 Assignement Report. Jakarta: WHO-VBCRU; 1983

48. Couprié B, Claudot Y, Same-Ekobo A, Issoufa H, Léger-Debruyne M, Tribouley J et al. Epidemiologic study of malaria in the rice-growing regions of Yagoua and Maga (North Cameroon). Bull Soc Pathol Exot Filiales. 1985;78:191-204.

49. Ijumba J, Lindsay S. Impact of irrigation on malaria in Africa: paddies paradox. Med Vet Entomol. 2001:15:1-11.

50. Nanfumba D, Tenywa M, Okui O, Majaliwa M, Wasige J, Lufafa A, et al. Characterisation of Anopheles mosquitoes breeding habitats in lowland rice fields in Uganda. JNSCl. 2011;9:44-57.

51. Laurence $B$. The biology of two species of mosquito, Mansonia africana (Theobald) and Mansonia uniformis (Theobald), belonging to the subgenus Mansonioides (Diptera, Culicidae). Bull Entomol Res. 1960;51:491-517.

52. Coetzee $M$, Craig M, le Sueur D. Distribution of African malaria mosquitoes belonging to the Anopheles gambiae complex. Parasitol Today. 2000;16:74-7.

53. Mbenda $H$, Awasthi $G$, Singh $P$, Gouado I, Das A. Does malaria epidemiology project Cameroon as 'Africa in miniature'? J Biosci. 2014;39:727-38.

54. Kenea O, Balkew M, Tekie T, Gebre-Michael T, Deressa W, Loha E, et al. Human-biting activities of Anopheles species in south-central Ethiopia. Parasit Vectors. 2016:9:527.

55. Kamau L, Mulaya N, Vulule J. Evaluation of potential role of Anopheles ziemanni in malaria transmission in western Kenya. J Med Entomol. 2006;43: 774-6. 
56. de Queiroz K. Species concepts and species delimitation. Syst Biol. 2007;56: 879-86.

57. Kudom A. Larval ecology of Anopheles coluzzii in Cape Coast, Ghana: water quality, nature of habitat and implication for larval control. Malar J. 2015;14: 447.

58. Tene-Fossog B, Ayala D, Acevedo P, Kengne P, Ngomo I, Makanga B, et al. Habitat segregation and ecological character displacement in cryptic African malaria mosquitoes. Evol Appl. 2015;8:326-45.

59. Kamdem C, Tene-Fossog B, Simard F, Etouna J, Ndo C, Kengne P, et al. Anthropogenic habitat disturbance and ecological divergence between incipient species of the malaria mosquito Anopheles gambiae. PLoS One. 2012;: $:$ 39453

60. Wondji C, Simard F, Fontenille D. Evidence for genetic differentiation between the molecular forms $\mathrm{M}$ and $\mathrm{S}$ within the Forest chromosomal form of Anopheles gambiae in an area of sympatry. Insect Mol Biol. 2002:11:11-9.

61. Wondji C, Simard F, Petrarca V, Etang J, Santolamazza F, Della Torre A, et al. Species and populations of the Anopheles gambiae complex in Cameroon with special emphasis on chromosomal and molecular forms of Anopheles gambiae s.s. J Med Entomol. 2005;42:998-1005.

62. Awono-Ambene P, Antonio-Nkondjio C, Toto J, Ndo C, Etang J, Fontenille $D$, et al. Epidemological importance of the Anopheles nili group of malaria vectors in equatorial villages of Cameroon, Central Africa. Afr J Med Med Sci. 2009;1:13-20.

63. Da D, Diabaté A, Mouline K, Lefèvre T, Awono-Ambene H, Ouèdraogo J, et al. Anopheles rufipes remains a potential malaria vector after the first detection of infected specimens in 1960 in Burkina Faso. J Infect Dis Ther. 2013;1:112.

64. Cohuet A, Simard F, Toto J, Kengne P, Coetzee M, Fontenille D. Species identification within the Anopheles funestus group of malaria vectors in Cameroon and evidence for a new species. Am J Trop Med Hyg. 2003;69:200-5.

65. Simard F, Ayala D, Kamdem G, Pombi M, Etouna J, Ose K, et al. Ecological niche partitioning between Anopheles gambiae molecular forms in Cameroon: the ecological side of speciation. BMC Ecol. 2009;9:17.

66. Kabbale F, Akol A, Kaddu J, Onapa A. Biting patterns and seasonality of Anopheles gambiae sensu lato and Anopheles funestus mosquitoes in Kamuli District. Uganda. Parasit Vectors. 2013;6:340.

67. Killeen G, Govella N, Lwetoijera D, Okumu F. Most outdoor malaria transmission by behaviourally-resistant Anopheles arabiensis is mediated by mosquitoes that have previously been inside houses. Malar J. 2016;15:225.

68. Wanji S, Mafo F, Tendongfor N, Tanga M, Tchuente F, Bilong Bilong C, et al. Spatial distribution, environmental and physicochemical characterization of Anopheles breeding sites in the Mount Cameroon region. J Vector Borne Dis. 2009;46:75-80.

69. Gnémé A, Guelbéogo W, Riehle M, Sanou A, Traoré A, Zongo S, et al. Equivalent susceptibility of Anopheles gambiae $\mathrm{M}$ and $\mathrm{S}$ molecular forms and Anopheles arabiensis to Plasmodium falciparum in Burkina Faso. Malar J. 2013;12:204

70. Wanji S, Tanke T, Atanga SN, Ajonina C, Tendongfor N, Fontenille D. Anopheles species of the mount Cameroon region: biting habits, feeding behaviour and entomological inoculation rates. Trop Med Int Health. 2003;8:643-9.

71. Chandler J, Boreham P, Highton R, Hill M. A study of the host selection patterns of the mosquitoes of the Kisumu area of Kenya. Trans R Soc Trop Med Hyg. 1975;69:415-25.

72. Maia M, Abonuusum A, Lorenz L, Clausen P, Bauer B, Garms R, et al. The effect of deltamethrin-treated net fencing around cattle enclosures on outdoor-biting mosquitoes in Kumasi, Ghana. PLoS One. 2012;7:e45794.

\section{Ready to submit your research? Choose BMC and benefit from:}

- fast, convenient online submission

- thorough peer review by experienced researchers in your field

- rapid publication on acceptance

- support for research data, including large and complex data types

- gold Open Access which fosters wider collaboration and increased citations

- maximum visibility for your research: over $100 \mathrm{M}$ website views per year

At BMC, research is always in progress.

Learn more biomedcentral.com/submissions 